\title{
Mechanical and Physical Properties of Fired Clay Brick Partial Doped with Coconut Shell Ash
}

\author{
Pius Rodney Fernando \\ Department of Physics, Faculty of Science, Eastern University, Chenkalady, Vanthrumoolai, Batticaloa, Sri Lanka
}

\section{Email address:}

Piusrf@gmail.com

\section{To cite this article:}

Pius Rodney Fernando. Mechanical and Physical Properties of Fired Clay Brick Partial Doped with Coconut Shell Ash. Journal of Energy and Natural Resources. Vol. 6, No. 5, 2017, pp. 58-63. doi: 10.11648/j.jenr.20170605.11

Received: September 19; Accepted: September 29, 2017; Published: November 20, 2017

\begin{abstract}
This study experimentally analyzed the engineering properties of the fired clay-coconut shell ash bricks. In this study 0 to $10 \%$ of coconut shell ash was blended with the brick clay. Main focus of this research was to utilize the natural agro waste for environmental protection, introducing low-cost eco-friendly building materials as well as to improve the selfemployments by practicing the traditional brick making method. For the analysis dry density, water absorption, compressive strength and flexural strengths were conducted on fired clay bricks by following the standard recommended testing machineries. The results reveal that the mechanical and physical properties improve with the doping of coconut shell ash. However, the optimum value of coconut shell ash to be doped for the manufacturing of fired clay bricks were originates to be $2 \%$.
\end{abstract}

Keywords: Coconut Shell Ash, Clay Brick, Alternative Building Material, Water Absorption, Compressive Strength, Flexural Strength, Sustainable Construction, Amorphous Silica

\section{Introduction}

Coconut is grown in more than 90 countries. Wherein, Sri Lanka is the fifth biggest, having cultivation of about $2,513,000$ metric tons of coconut per year [1]. However, it is also the main contributor to the country's pollution problem as a stable waste within the form of shells. This waste may be applied as an alternative for either pleasant or coarse combination or in clay brick manufacturing.

Coconut shells ash as cement research suggests that maximum materials which are in rich may be utilized in partial alternative of cement (binder). It has also been established that amorphous silica determined in some pozzolanic substances which react with lime extra effortlessly than the ones of crystalline form [2-5]. Use of such pozzolana can cause growth in compressive and flexural strengths $[6,7]$. The raw materials used for the producing of cement consist mainly of lime, silica, alumina, and iron oxide Normally the chemical analysis of coconut shell ash wellknown shows that it contains some portions of those elements [8]. As a result coconut shells ash may be used correctly as a supplementary cementations material.

In this paper, the influence of coconut shells ash with replacement of fired clay brick is investigated. The purpose of this research is to determine the suitability of coconut shell ash (CSA) with partial substitute of clay, impact on strength, low cost, eco-friendly and to introduce the usage of natural agro waste materials with green environment.

\section{Experimental Methodology}

\subsection{Materials}

\subsubsection{Brick Clay}

The brick clay for this research was collected from Verpavettuvan, at the depth of 1 to $1.5 \mathrm{~m}$ below the surface ground, which is one of the most popular places for clay brick (located in Batticaloa District, Eastern Province of Sri Lanka). The chemical analyses were carried out for the collected samples, which clearly confirm that the major chemical compositions of the clay are silica, alumina, and ferric oxide, are given in Table 1. The higher silica percentage in the clay increases the strength of the clay brick [9]. 
Table 1. The chemical composition of brick clay.

\begin{tabular}{|c|c|c|c|c|c|c|c|c|c|c|c|}
\hline Oxide compositions (\%) & $\mathrm{SiO}_{2}$ & $\mathrm{Fe}_{2} \mathrm{O}_{3}$ & $\mathbf{A l}_{2} \mathbf{O}_{3}$ & $\mathrm{CaO}$ & MgO & $\mathrm{SO}_{3}$ & $\mathrm{Na}_{2} \mathrm{O}$ & $\mathbf{K}_{2} \mathbf{O}$ & $\mathrm{TiO}_{2}$ & $\mathbf{P}_{2} \mathbf{O}_{3}$ & LIO \\
\hline Present study & 63.10 & 9.23 & 10.63 & 5.03 & 0.02 & 0.01 & 1.03 & 0.02 & - & - & 8.23 \\
\hline Badr El-Din et al. [10] & 65.20 & 7.36 & 15.26 & 1.01 & 0.83 & 0.08 & 3.12 & 0.62 & 1.92 & 0.15 & 6.01 \\
\hline
\end{tabular}

\subsubsection{Water}

Fresh water was used to mix the materials, which was free from organic matters of any type as described in Sri Lankan Standards 522: Part 1:1989 [11]. It activates the chemical reaction between the CSA and with clay materials and forms clay glue.

\subsubsection{Coconut Shell Ash (CSA)}

The coconut shells were acquired from kitchen waste sell off in Batticaloa, Eastern Region, Sri Lanka. They were finally spread on matting and allowed to properly dry to facilitate right combustion at some point of burning. This material changed into burnt into ashes in a furnace at a temperature range of 500 to $550^{\circ} \mathrm{C}$ for two hours to provide the coconut is discovered that the liquid restrict is minimal while CSA delivered is $4 \%$, the plastic restriction increases with boom in \%CSA content however the variant is marginal. Then the ash was allowed to cool and kept in an air tide container. The oxide compositions were investigated and tabulate in Table 2 and compared with the previous studies.

Table 2. The oxide compositions of Coconut Shell Ash (CSA).

\begin{tabular}{|c|c|c|c|}
\hline Oxide compositions (\%) & Present study & B. W. Isah [12] & J. T. Utsev and J. K. Taku [8] \\
\hline $\mathrm{SiO}_{2}$ & 43.5 & 44.05 & 37.97 \\
\hline $\mathrm{Al}_{2} \mathrm{O}_{3}$ & 15.2 & 14.60 & 24.12 \\
\hline $\mathrm{Fe}_{2} \mathrm{O}_{3}$ & 12.6 & 12.40 & 15.48 \\
\hline $\mathrm{CaO}$ & 3.25 & 4.57 & 4.98 \\
\hline $\mathrm{MgO}$ & 15.01 & 14.20 & 1.89 \\
\hline $\mathrm{MnO}$ & 0.19 & 0.22 & 0.81 \\
\hline $\mathrm{Na}_{2} \mathrm{O}$ & 0.47 & 0.45 & 0.95 \\
\hline $\mathrm{ZnO}$ & 0.5 & 0.30 & - \\
\hline $\mathrm{P}_{2} \mathrm{O}_{5}$ & 0.4 & - & 0.32 \\
\hline $\mathrm{SO}_{3}$ & - & - & 0.71 \\
\hline LOI & 8.39 & 8.69 & 11.94 \\
\hline
\end{tabular}

\subsection{Manufacture of Clay Bricks}

In this study, six series of Clay-CSA bricks were cast in Sri Lankan standard size: $20.5 \mathrm{~cm} \times 9.5 \mathrm{~cm} \times 7.5 \mathrm{~cm}$ dimension and in different CSA ratios from 0 to $10 \%$ with a step of $2 \%$. For each mixing levels 3 bricks were cast. For this study, traditional mixing method was employed, and the materials were turned over a number of times until to get the good consistency mixture. Water was integrated as required, and the materials were further turned over to secure adhesion. It was then placed into the mould, compacted and smoothened. After removing form the mould clay bricks were protected by saw dust to avoid engaging with other newly prepared clay bricks. These green clay bricks were subjected to direct air dry under sunlight of temperature around $35^{\circ} \mathrm{C}$ for one week. Then the clay bricks were burned in a brick kiln of burning temperature range $600^{\circ} \mathrm{C}$ to $850^{\circ} \mathrm{C}$, which is the industrial scale manufacturing process of fired clay bricks in the Eastern region of Sri Lanka. The burning process was continuously carried out for two days and kept about one week. The properties of the fired bricks were analyzed.

\section{Analyzes of Brick Properties}

Water absorption, Compressive strength and Flexural strength were analyzed and the results of these properties were compared with the Sri Lankan and British Standards.

\subsection{Particle Size Analysis}

Particle analysis can be done by different size of sieves, but here this test was not done, because the aim of the research was to disseminate the knowledge to the local markets and improve the self-employment of the local community.

\subsection{Water Absorption (WA) Analysis}

The water absorption property was analyzed as per SLS 855: Part 2: 1989 [13]. This should be in the limit of 12 to $20 \%$ as per the BS 5628: Part 1:2005 [14] and Indonesian Standard SNI 15-2094-2000 [15]. This property not a requirement as indicated in SLS 855: Part 1: 1989 [13]. However, it is a useful unique property to determine some other parameters. Water absorption property of the blocks was analyzed for three bricks in each set. Initially, bricks were kept under the sunlight of temperature of $35^{\circ} \mathrm{C}$ to $40^{\circ} \mathrm{C}$ for one day and the dry weights were measured. These bricks were immersed in the water for one day and the wet weight was measured. Water absorption is presented as a percentage was calculated using the below equation, and the average value was calculated for each set of blocks.

$$
\mathrm{WA}=\left[\left(M_{\mathrm{WW}}-M_{\mathrm{DW}}\right) / M_{\mathrm{DW}}\right] \times 100 \%
$$

Where $M_{\mathrm{DW}}$ - mass of the dry block and $M_{\mathrm{WW}}$ - mass of the wet block after 24 hours. 


\subsection{Compressive Strength (CS) Analysis}

Compressive strength analyses were done using Universal Testing Machine available in the Department of Physics, Eastern University, Sri Lanka. The testing procedure was performed according to the Sri Lankan Standards 855: Part 1: 1989 [13], which is similar to ASTM C67-05. The maximum force applied to break the block, with and length of the block was recorded. Three blocks from each set were measured and average compressive strength was determined, compared with the Sri Lankan standards.

$$
C S=\text { Applied force at the peak / Area of the block }
$$

\subsection{Flexural Strength (FS) Analysis}

Three point twisting test was done according to the Sri
Lankan Principles 855: Part 1: 1989 [13] to decide the flexural quality of the block which is like the ASTM D136505 standard. The setup of the block for the estimation is appeared in the figure 3. The braking power and the width of the block were recorded to decide the flexural quality (FQ).

$$
M R=F L / w h^{2}=3 F a / 2 w h^{2}
$$

Where $M R$ is flexural strength, $(\mathrm{kPa}), L$ is span length, $(\mathrm{mm}), w$ and $h$ are width and height of the block, $(\mathrm{mm})$ respectively, $a$ is distance between line of fracture and the nearest support, $(\mathrm{mm})$, and $F$ is maximum applied load $(\mathrm{kN})$.

\section{Results and Discussion}

The physical properties as a function of \%CSA are graphically expressed below:

\subsection{Density}

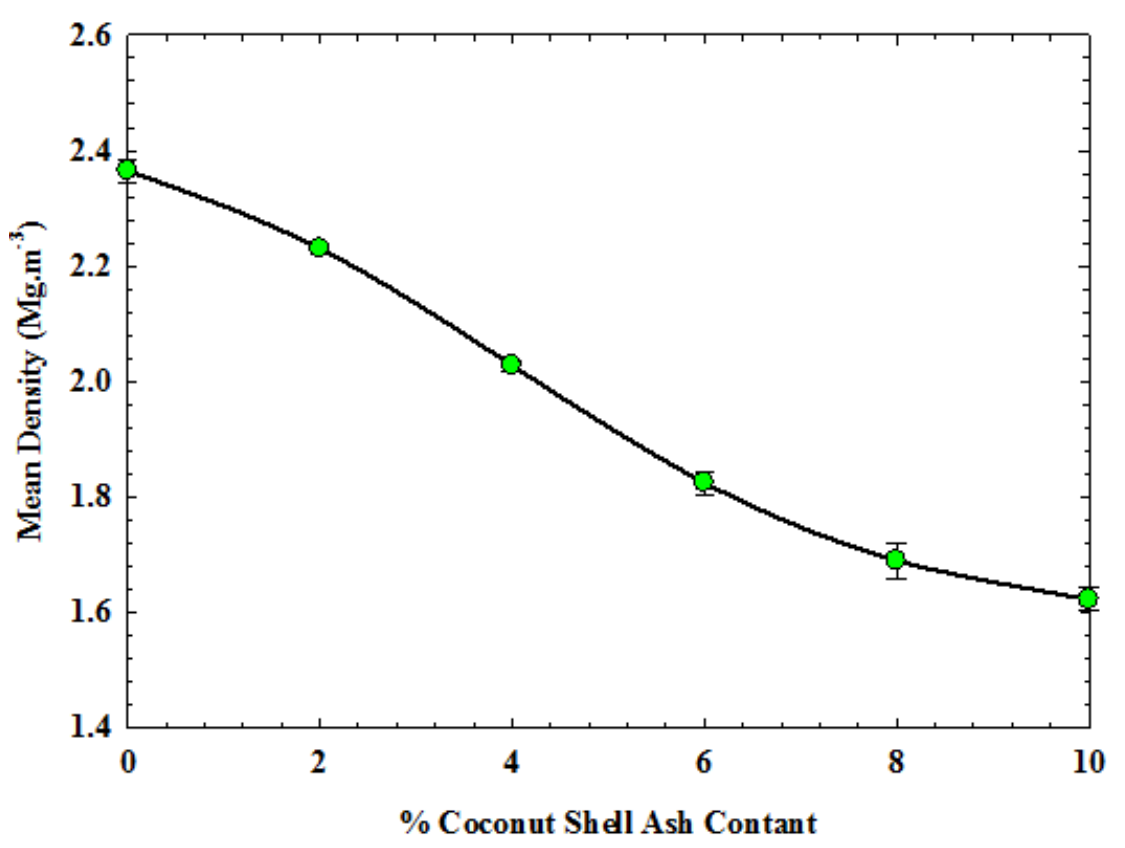

Figure 1. The mean density as a function of CSA from 0 to $10 \%$. The error values are lying with the data points.

As shown in the figure 1, the mean density of the brick smoothly decreases with the increase CSA doping percentage. The decreasing behavior can be attributed to coating of the clay by the CSA that result to large particles with larger voids and less density [16]. The brick doped with CSA $\leq 4 \%$ satisfy the standard requirement as per BS 3921:1982 British standard specifications for clay brick which stated the minimum density of $2.0 \mathrm{Mg} \cdot \mathrm{m}^{-3}$ [17].

\subsection{Water Absorption}

Water absorption property can be used as one of an indicator to analyse the quality of the sample. Figure 2 portrays change of the water absorption for the fired clay brick that contains CSA. In general, the water absorption decreases from $16.4 \%$ to $14.6 \%$ as the CSA increases from $0 \%$ to $2 \%$. Thereafter the property sharply increases with increasing the CSA up to $6 \%$ and the smoothly increases up to $10 \%$ of CSA. This indicates that CSA plays a major role in clay-CSA mixture. According to the results, all the brick, satisfy recommended value of $20 \%$ as per the Indonesian Standard SNI 15-2094-2000 [14] and 12\% as per the British Standard BS 5628: Part 1:2005 [15] which lie within the standard values. Moreover, the water absorption of $2 \%$ CSA brick is lower than the conventional brick with a difference of $1.2 \%$ absorption. The behaviour of water absorption above $2 \%$ might be due to porosity increases with doping of CSA. 


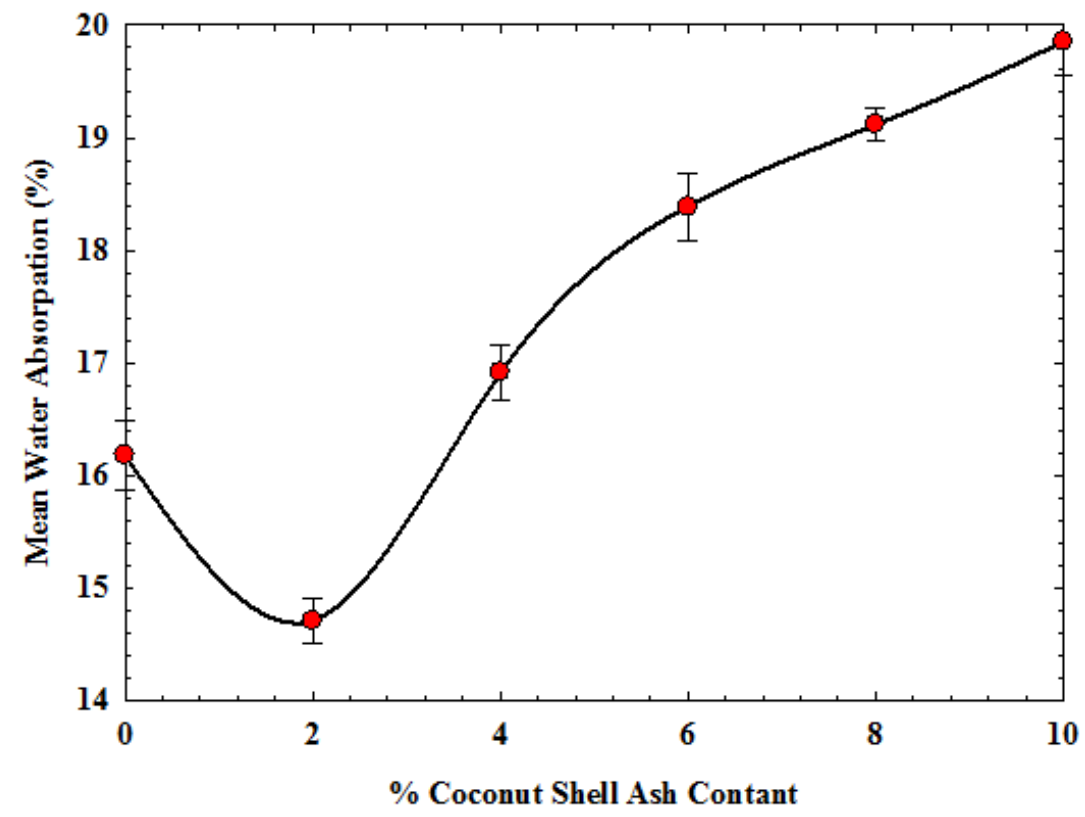

Figure 2. The mean water absorption as a function of CSA from 0 to 10\%. The error values are lying with the data points.

\subsection{Compressive Strength}

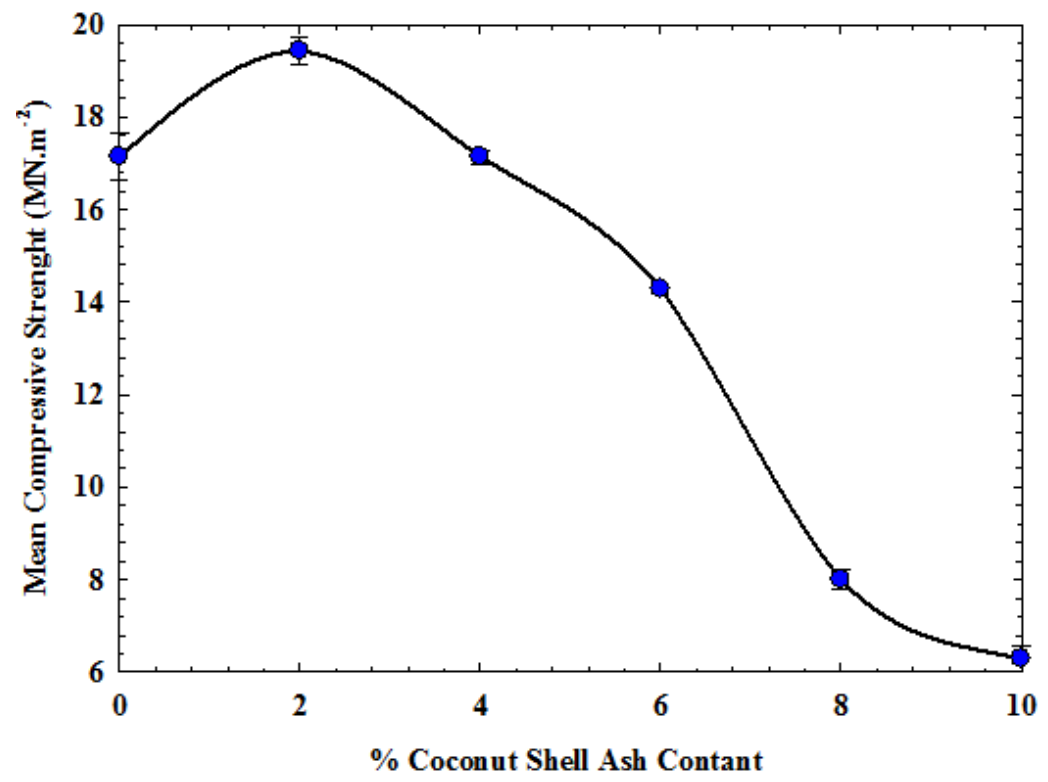

Figure 3. The mean compressive strength as a function of CSA from 0 to $10 \%$. The error values are lying with the data points.

The mean compressive strength of the CSA fired clay bricks obtained in the present study was compared with the study by Isah [12]. Summering the both studies show a small variations in the compressive strength, that may be due to the change in the chemical properties of the CSA and brick clay. The figure 3 clearly shows that the mean compressive strength increases up to $2 \%$ follows that decreases with increase doping percentage of CSA. The compressive strength of $2 \%$ brick is higher than the conventional brick with the value of $19.43 \mathrm{MN} \cdot \mathrm{m}^{-2}$ and $17.14 \mathrm{MN} \cdot \mathrm{m}^{-2}$ respectively. The increase in the compressive strength is due to higher percentage of $\mathrm{SiO}_{2}$ that stabilize the clay material. Therefore, $2 \% \mathrm{CSA}$ is the maximum optimal dosage and a suitable agent to stabilize the brick clay and the compressive strength.

\subsection{Flexural Strength}

From figure 4, it can be clearly seen that when doping the brick clay with CSA a significant decrease in flexural strength is obtained. However, it can be seen that the flexural strength increases up to $2 \% \mathrm{CSA}$ doping. However, the

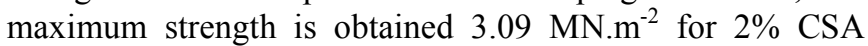
brick is the optimal value, which is higher than the

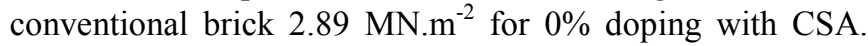
The behavioral change in the flexural strength is very similar to the compressive strength. 


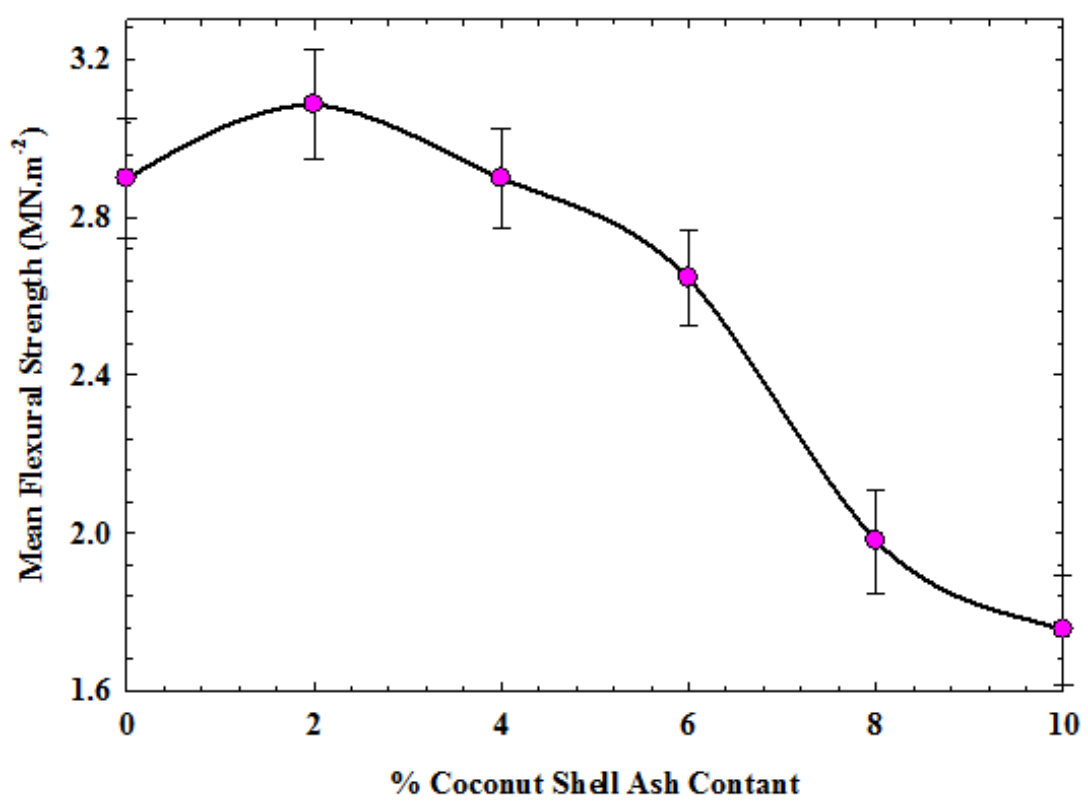

Figure 4. The mean flexural strength as a function of CSA from 0 to 10\%. The error values are lying with the data points.

\subsection{Relationship between Compressive Strength and Flexural Strength}

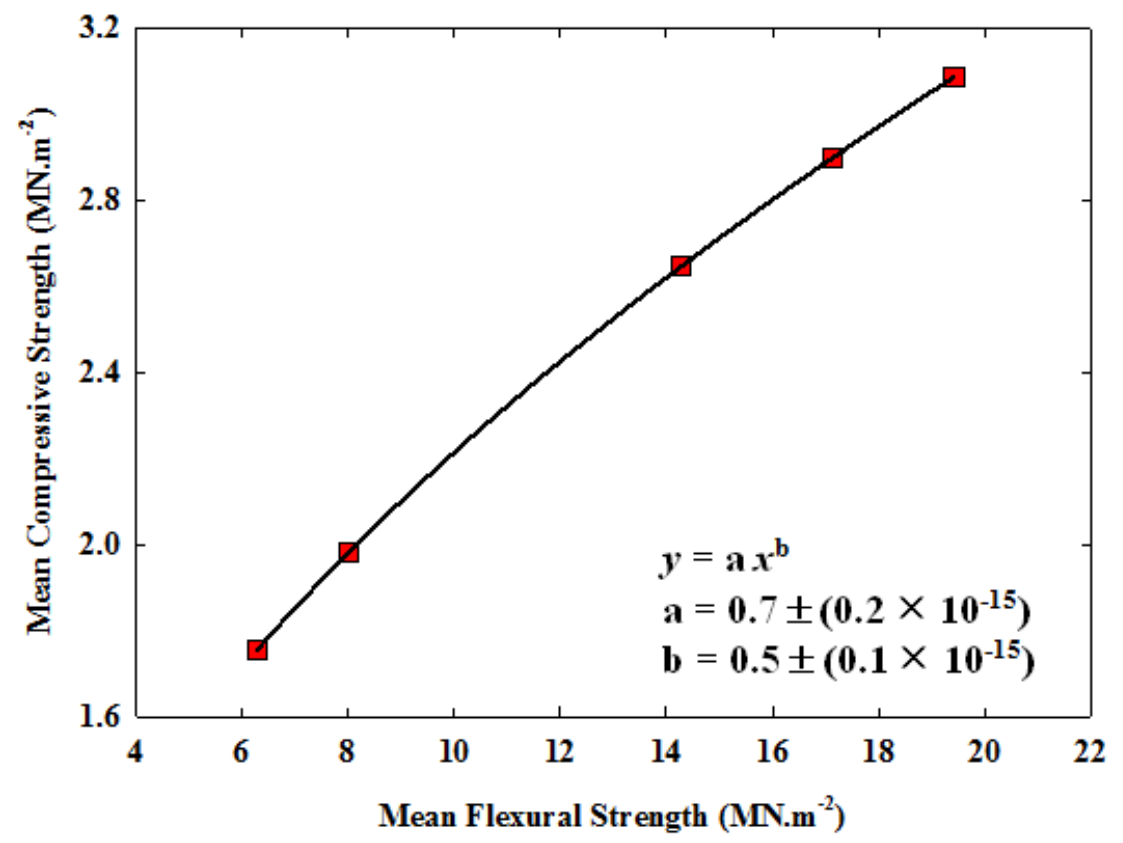

Figure 5. The relationship between mean compressive strength and flexural strength of the CSA mixed fired clay bricks.

Relationship between the mean compressive strength and the mean flexural strength of the CSA doped clay bricks are shown in the figure 5 . The relationship between the compressive and flexural strength is given by $F_{t}=$ $0.7\left(F_{c k}\right)^{0.5}$ for normal masonry block. Where $F_{t}$ is the flexural strength and $F_{c k}$ is the compressive strength of the block. The power law fit to the data points satisfy the relationship in the form $y=\mathrm{a} x^{\mathrm{b}}$, where $\mathrm{a}=0.7 \pm\left(0.2 \times 10^{-15}\right)$ and $b=0.5 \pm\left(0.1 \times 10^{-15}\right)$. These constants can be varied with respect to the type of materials.

\section{Conclusion}

From various physical properties studies performed by doping different percentage of CSA, it could be concluded that doping of CSA improve the physical properties of the fired clay bricks within the limit of experimental error.

The results obtained from this analysis revealed that doping of $2 \%$ CSA provides optimum values in the physical properties and are given as follows: The maximum mean dry density $2.23 \mathrm{Mg} \cdot \mathrm{m}^{-3}$ was recorded and satisfy the 
requirements as per BS 3921: British standard specifications for brick clay which stated the minimum density of 2.0 $\mathrm{Mg} \cdot \mathrm{m}^{-3}$. According to the results, all the brick, satisfy recommended water absorption value of $20 \%$ as per the Indonesian Standard SNI 15-2094-2000 and 12\% as per the British Standard BS 5628: Part 1:2005 which lie within the standard values. The maximum compressive and flexural strength $19.43 \mathrm{MN} . \mathrm{m}^{-2}$ and $3.09 \mathrm{MN} . \mathrm{m}^{-2}$ were recorded respectively. According to the BS 3921, compressive strength of the fired clay brick should be greater than 5 MN.m-2. For a single story building minimum compressive strength should be within the range 1 to $5 \mathrm{MN} \cdot \mathrm{m}^{-2}$ and recommended by the building authorities. The power law fit obeys the relationship $y=\mathrm{a} x^{\mathrm{b}}$, where $\mathrm{a}=0.7 \pm\left(0.2 \times 10^{-15}\right)$ and $b=0.5 \pm\left(0.1 \times 10^{-15}\right)$. These constants can be varied with respect to the type of materials.

The new born clay bricks are not suite for high strength external construction, because their low strength and the wet environments will be affect the structural integrity. However, the bricks reduces the overall weight of the building due to low density and weight. Thus, the bricks can be used for interior wall partitions and decorations.

This new clay bricks can be manufactured on site itself, low cost, semi labour skills and local economy will flourish. Not only has that by introducing the use of locally available natural agro waste materials directed to ecological structure.

Therefore, $2 \%$ CSA could be suggested for use in enlightening the physical properties of the fired clay bricks than the conventional fired clay brick.

\section{Acknowledgements}

The creators express their appreciation to the staff of Laboratory, Department of Physics, Maintenance, Eastern University, Sri Lanka and Eastern University, Sri Lanka, for giving the best possible offices to finish this work.

\section{References}

[1] FAOSTAT data, 2016 (last accessed by Top of Anytime: January 2016.

[2] Aho M. I. and Utsev J. T. Compressive Strength of Hollow Sandcrete Blocks Made with Rice Husk Ash as a Partial Replacement to Cement. Nigerian Journal of Technology. Vol. 27, No. 2, 2008, pp. 71-77.

[3] Tyagher S. T, Utsev J. T. and Adagba, T. Suitability of saw dust ash-lime mixture for production of Sandcrete hollow blocks, Nigerian Journal of Technology. Vol. 30, No. 1, 2011, pp. $79-84$.

[4] Naji A. G, Adbdul Rasheed S, Aziz A. F. N. and Salleh M. A. M. Contribution of rice husk ash to the properties of mortal and concrete; a review. Journal of American Science. Vol. 6, No. 3, 2010, pp. 157-165.

[5] Nwadiogbu C. P. Effect of elapsed time on laterite modified with lime and locust beans waste ash. Unpublished M. Sc research proposal submitted to post Graduate school, Ahmadu Bello University Zaria. 2010.

[6] Oyetola E. B. and Abdullahi M. The use of rice husk ash in low cost sandcrete blocks production. Leonardo Electronic Journal of practices and Technology. Vol. 8, 2006, pp. 58-70.

[7] Okpala D. C. Rice Husk Ash as Partial replacement in concrete: The Nigeria Society of Engineers, Annual conference proceedings, Port Harcourt. 1987, pp. 22-41.

[8] Utsev J. T and Taku J. K. Coconut Shell Ash as Partial Replacement of Ordinary Portland Cement In Concrete Production. International Journal of Science \& Technology Research. Vol. 1, No. 8, 2012, pp. 86-89.

[9] De Silva P. and Crenstil K. S. The Effect of $\mathrm{Al}_{2} \mathrm{O}_{3}$ and $\mathrm{SiO}_{2}$ on Setting and Hardening of $\mathrm{Na}_{2} \mathrm{O}-\mathrm{Al}_{2} \mathrm{O}_{3}-\mathrm{SiO}_{2}-\mathrm{H}_{2} \mathrm{O}$ Geopolymer Systems. Journal of Australian Ceramic Society. Vol. 44, No. 1, 2008, pp. 39-46.

[10] Badr El-Din Ezzat Hegazy, Hanan Ahmed Fouad and Ahmed Mohammed Hassanain. Incorporation of water sludge, silica fume, and rice husk ash in brick making. Advances in Environmental Research. Vol. 1, 2012, pp. 83-96.

[11] Sri Lankan Standards Specification (SLS). Cement Block 855 Part 1 Requirements. Sri Lanka Standard Institute, Dharmapala Mawatha, Colombo 3, Sri Lanka. 1989.

[12] Iash B. W. Effect of Coconut Shell Ash on Properties of Fired Clay Brick. Journal of Civil Engineering and Environmental Technology. Vol. 1, No. 6, 2014, pp. 7-11.

[13] Sri Lankan Standards Specification (SLS). Cement Block 855 Part 1 Requirements. Sri Lanka Standard Institute, Dharmapala Mawatha, Colombo 3, Sri Lanka. 1989.

[14] British Standard 5628: Part 1: code of practice for the use of masonry. Structural use of unreinforced masonry. 2005.

[15] SNI 15-2094-2000. Massive red bricks for masonry works, National Standardization Agency of Indonesia.

[16] Osula D. O. A. Lime Modification of Problem Laterite. Engineering Geology. Vol. 30, 1991, pp. 142-149.

[17] BS 3921: British Standard Specification for Clay Bricks. 1985. 